\title{
Survei Sarana dan Prasarana Penunjang Pembelajaran Pendidikan Jasmani Olahraga dan Kesehatan (PJOK)
}

\author{
Ida Bagus Putu Oka Mahendra ${ }^{1 *}$, I Ketut Budaya Astra ${ }^{2}$, I Ketut Semarayasa ${ }^{3}$ iD \\ ${ }^{123}$ Prodi Pendidikan Jasmani Kesehatan dan Rekreasi, Jurusan Pendidikan Olahraga, Fakultas Olahrga dan Kesehatan, \\ Universitas Pendidikan Ganesha, Singaraja, Bali \\ *Corresponding author: gustumarnot@gmail.com
}

\begin{abstract}
Abstrak
Salah satu faktor keberhasilan proses pembelajaran adalah ketersediaan sarana dan prasarana yang baik. Sehingga tiap sekolah harus memperhatikan keresedian sarana dan prasarana yang dimiliki. Tujuan penelitian ini adalah untuk mengetahui sarana dan prasarana penunjang pembelajaran PJOK tingkat SMA di Kecamatan Karangasem pada tanggal 28 Agustus 2020. Desain penelitian ini adalah penelitian deskriptif kuantitatif, dengan menggunakan metode Survei. Populasi penelitian ini adalah seluruh SMA yang ada di kabupaten Karangasem. Teknik pengambilan sampel dalam penelitian ini dilakukan dengan observasi langsung tepatnya dengan melakukan pengamatan langsung terhadap sumber data atau objek penelitian, dan mencatat data yang diperlukan menggunakan lembar observasi. Dari 37 jenis sarana total seluruhnya yaitu sebanyak 927 buah yang berkondisi baik yaitu berjumlah 825 atau dengan rata-rata 22,30 dan memiliki persentase $85 \%$. sedangkan yang berkondisi buruk berjumlah 102 dengan rata-rata 2.76 dengan persentase $15 \%$. Pada status kepemilikan sarana penunjang pembelajaran PJOK di SMA se- Kecamatan Karangasem dibedakan menjadi 2 kategori yaitu milik sekolah dan meminjam/menyewa. Dari 927 jumlah keseluruhan atau total sarana yang dimiliki 877 dengan rata-rata 23,70 dan memiliki persentase $67 \%$ milik sekolah. Prasarana yang tersedia ada 6 jenis yang seluruhnya termasuk kedalam fasilitas. Dari jumlah total atau kesulurannya yaitu berjumlah 41 dengan rata-rata 6,8 dan persentase 100\% berkondisi baik. Dari segi status kepemilikan prasarana, fasilitas \}milik sekolah yaitu 8 dengan rata-rata 1,33 dan dengan rata-rata persentase $19 \%$, kemudian untuk fasilitas yang meminjam/menyewa berjumlah 33 dengan rata-rata 5,5 dan dengan rata-rata persentase $81 \%$. Maka dapat disimpulkan bahwa sarana dan prasarana penunjang pembelajaran PJOK di SMA Negeri se-Kecamatan Karangasem secara keseluruhan dapat dikatakan sudah cukup baik, namun perlu pengelolaan yang baik.
\end{abstract}

Kata Kunci: Survei, Sarana, Prasarana

\section{Abstract}

One of the success factors of the learning process is the availability of good facilities and infrastructure. Each school must pay attention to the availability of facilities and infrastructure owned. This study aimed to determine the facilities and infrastructure supporting learning PJOK at the SMA level in Karangasem District on August $28^{\text {th }}, 2020$. The design of this study was a quantitative descriptive study using the survey method. The population of this research is all senior high schools in Kecamatan Karangasem. The sampling technique in this study was carried out by direct observation, precisely by making direct observations. The data source or research object and recording the required data using an observation sheet of the 37 types of facilities, a total of 927 units are in good condition, which is 825 or with an average of 22.30 and has a percentage of $85 \%$. At the same time, those in bad condition amounted to 102 with an average of 2.76 with a percentage of $15 \%$. The ownership status of PJOK learning support facilities in Karangasem District High School is divided into two categories, namely school-owned and borrowed/rented. Of the 927 total or total facilities owned, 877 with an average of 23.70 and $67 \%$ owned by schools. There are 6 types of available infrastructure, all of which are included in the facility. The total number of vines, which amounted to 41 with an average of 6.8 and a percentage of $100 \%$ in good condition in terms of infrastructure ownership status, facilities owned by schools are 8 with an average of 1.33 and an average percentage $19 \%$. For facilities that are borrowed/rented, there are 33 with an average of 5.5 and an average percentage $81 \%$. So it can be concluded that the supporting facilities and infrastructure for PJOK learning in public high schools in Kecamatan Karangasem as a whole can be said to be quite good but need good management.

Keywords: Surveys, Facilities, Infrastructure

\section{History:}

Received: 24 September 2020

Revised: 1 Oktober 2020

Accepted: 26 Oktober 2020

Published: 7 November 2020
Publisher: Undiksha Press

Licensed: This work is licensed under

a Creative Commons Attribution 3.0 License

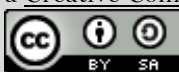




\section{Pendahuluan}

Pendidikan merupakan bagian yang sangat penting untuk membangun suatu Negara. Salah satu unsur pendukung untuk menciptakan pendidikan yang berkualitas adalah sumber Daya Manusia (SDM). Untuk membantu menciptakan SDM yang unggul disini pemerintah diperlukan peran aktif dalam pembangunan pendidikan secara formal maupun non formal.

Pendidikan jasmani, olahraga, dan kesehatan itu sendiri merupakan bagian integral dari pendidikan secara keseluruhan yang bertujuan untuk mengembangkan aspek kebugaran jasmani, keterampilan gerak, keterampilan berfikir kritis, keterampilan sosial, penalaran, stabilitas emosional, tindakan moral, aspek pola hidup sehat dan pengenalan lingkungan bersih melalui aktifitas jasmani, olahraga, dan kesehatan terpilih yang direncanakan secara sistematis dalam rangka mencapai tujuan pendidikan nasional tercakup ke dalam ruang lingkup mata pelajaran pendidikan jasmani olahraga dan kesehatan yang ada di sekolah meliputi aspek: permainan olahraga, aktifitas pengembangan, aktifitas senam, aktifitas ritmik, dan kesehatan (Natal \& Bate, 2020).

SDM yang unggul tidak cukup memiliki keahlian dan keterampilan saja, SDM juga harus sehat secara jasmani dan memiliki fisik yang kuat. Sebuah penelitian di Inggris, yang dilakukan pada juni 2015 dan dipublikasikan di laman resmi Journal Psychology \& Behavior, menemukan fakta-fakta bahwa olahraga yang dilakukan secara teratur pada masa kanakkanak, remaja, dan lanjut usia mempunyai dampak meningkatkan potensi untuk memiliki badan yang tetap aktif dan sehat secara fisik sampai usia (usia produktif), mereka yang sejak usia sekolah rajin dan rutin melakukan olahraga dilaporkan jarang sakit semasa dewasanya. Oleh karena itu PJOK dirasa perlu diberikan pada anak-anak usia sekolah, karena untuk mendapatkan suatu kondisi badan sehat dan bugar di masa dewasa didapat melalui suatu proses yang panjang dari usia dini, yaitu usia sekolah sampai dewasa kelak. Menurut Suryobroto (2004:8) "Tujuan pendidikan jasmani untuk membentuk anak yaitu sikap mental atau nilai, kecerdasan fisik dan ketrampilan (psikomotorik), sehingga siswa akan dewasa dan mandiri yang nantinya akan dapat digunakan dalam kehidupannya"

Menurut Undang-Undang No. 20 tahun 2003, tentang Sistem Pendidikan Nasional, BAB XII Pasal 45 : "Setiap satuan pendidikan formal dan non formal menyediakan sarana dan prasarana yang memenuhi keperluan pendidikan sesuai dengan pertumbuhan dan perkembangan potensi fisik, kecerdasan intelektual, sosial, emosional, dan kejiwaan peserta didik". Dalam Undang-Undang tersebut dijelaskan bahwa setiap satuan formal dalam hal ini sekolah-sekolah diharapkan menyediakan sarana dan prasarana dalam menunjang proses pembelajaran, tidak terkecuali untuk mata pelajaran PJOK.

Pendidikan jasmani tidak sekadar membangun segi kejasmanian melainkan juga untuk kesejahteraan jasmani. Melalui kegiatan ini hendaklah tertanamkan norma-norma pegangan hidup yang positif, agar dapat berdiri sendiri sebagai operasional yang tidak merugikan orang dan juga diri sendiri. sebagaimana tercantum dalam undang-undang keolahragaan Nasional Menpora Nomor : 3 tahun 2005 dalam Bab XI pasal 3 dan 4 yang berbunyi sebagai berikut: "Jumlah dan jenis prasarana olahraga yang dibangun harus memperhatikan potensi keolahragaan yang berkembang didaerah setempat. Prasarana olahraga yang dibangun di daerah wajib memenuhi jumlah dan standar minimum yang ditetapkan oleh pemerintah"(Nursalam, 2016, 2013).

Pembelajaran pendidikan jasmani dapat berjalan dengan sukses dan lancar sangat ditentukan oleh beberapa unsur antara lain guru, siswa, kurikulum sarana dan prasarana, tujuan, metode, lingkungan yang mendukung, dan penilaian. Guru merupakan unsur yang paling menentukan keberhasilan proses pembelajaran. Sarana dan prasarana pendidikan jasmani merupakan salah satu unsur penunjang keberhasilan pembelajaran. Sarana dan prasarana pendidikan jasmani diperlukan dalam pembelajaran pendidikan jasmani di sekolah, 
karena tanpa ada sarana dan prasarana menjadikan pembelajaran tidak berjalan dengan baik (Purnama \& Siliwangi, 2017).

Adanya sarana dan prasarana yang memadai dalam suatu lembaga pendidikan yaitu sekolah-sekolah akan menunjang dan mempermudah seorang guru dan peserta didik dalam mempraktekan materi pelajaran olahraga. Oleh karena itu, sarana dan prasarana sangat berperan penting dalam pencapaian pembelajaran PJOK yang optimal.

Guru akan mudah memberi pengarahan dan praktek suatu gerakan olahraga pada siswa secara langsung dengan menggunakan sarana yang ada, begitu pula dengan para siswa, mereka akan lebih giat dan semangat belajar olahraga karena adanya lapangan dan alat-alat olahraga yang dapat mereka gunakan. Menurut (Suryobroto, 2004), "Sarana dan prasarana pendidikan jasmani salah satu faktor penunjang keberhasilan pendidikan jasmani dan merupakan unsur yang menjadi masalah dimana-mana, khususnya di Indonesia".

Sarana dan prasarana merupakan faktor penting dalam menunjang keberhasilan pembelajaran PJOK tapi sarana dan prasarana ini juga menjadi masalah yang kerapkali ditemui di sebagian besar sekolah-sekolah di Indonesia. Ada beberapa faktor yang menjadi penyebab minimnya sarana dan prasarana olahraga yang ada di sekolah-sekolah, seperti kurangnya anggaran dana untuk penyediaan sarana dan prasarana olahraga, atau dapat juga sempit/ kurangnya lahan sekolah, sehingga sekolah tidak mungkin membuat lapangan olahraga di area sekolah. Menurut Agus, S. Suryobroto (2004: 4) sarana atau alat adalah segala sesuatu yang diperlukan dalam pembelajaran pendidikan jasmani olahraga dan kesehatan, mudah dipindah bahkan dibawa oleh pelakunya/siswa. Sarana atau alat sangat penting dalam memberikan motivasi anak didik untuk bergerak aktif, sehingga siswa sanggup melakukan aktivitas dengan sesungguhnya dan akhirnya tujuan aktivitas dapat tercapai. Prasarana adalah segala sesuatu yang diperlukan dalam pembelajaran penjas, bersifat permanen atau tidak dapat dipindahpindahkan. Menurut Saryono dan Hutomo (2016) Sarana dan prasarana merupakan salah satu unsur penunjang keberhasilan pendidikan Jasmani, mengingat mata pelajaran tersebut membutuhkan banyak sarana dan prasarana yang digunakan untuk menunjang tercapainya pembelajaran yang efektif. Menurut (Fatmawati, Nur. Andi Mappincara, 2019) sarana dan prasarana pendidikan yaitu segala perlengkapan/ fasilitas yang digunakan dalam proses pembelajaran baik yang bergerak maupun tidak bergerak seperti kursi, meja, ruang kelas dan lain-lain dalam rangka pencapaian tujuan pendidikan. Menurut (Ismaya, 2015) Sarana prasarana merupakan fasilitas pendukung yang dapat menunjang proses kegiatan dalam organisasi apa saja termasuk di dalamnya adalah satuan pendidikan atau sekolah Menurut (Megasari, 2014) Pengelolaan sarana dan prasarana sangat penting karena dengan adanya pengelolaan sarana dan prasarana lembaga pendidikan akan terpelihara dan jelas kegunaanya. Dalam pengelolaan pihak sekolah harus dapat bertanggung jawab terhadap sarana dan prasarana terutama kepala sekolah yang langsung menangani sarana dan prasarana tersebut. Dan pihak sekolahpun harus dapat memelihara dan memperhatikan sarana dan prasarana sekolah yang sudah ada. Maka dengan adanya sarana dan prasarana di sekolah siswa dapat belajar dengan maksimal dan seefesien mungkin. Jadi pengelolaan terhadap sarana dan prasarana harus lebih ditekankan lagi dalam lembaga pendidikan seperti sekolah. Dan harus ada yang bertanggung jawab atas pengelolaan sarana dan prasarana tersebut. Dengan pengelolaan sarana dan prasarana yang ada di sekolah kepala sekolah dapat merencanakan dan mendata apa saja sarana dan prasarana yang harus digunakan di sekolah tersebut. Jika semua langkah-langkah pengelolaan telah berjalan dengan baik seperti yang diharapkan maka akan berdampak positif terhadap siswa-siswa dalam proses belajar mengajar dan tercapainya tujuan pendidikan secara efektif dan efisien. Maka penyelenggara pendidikan baik itu pemerintah, kepala sekolah, guru, personil sekolah yang lainnya maupun masyarakat perlu terus berusaha untuk meningkatkan kualitas pendidikan sesuai dengan tuntutan zaman. 
Masalah tentang minimnya sarana dan prasarana olahraga di sekolah-sekolah, bukan masalah yang sederhana karena banyak faktor yang menjadi penyebabnya diantaranya terbatasnya alokasi dana untuk penyediaan sarana dan prasarana PJOK, dan jumlah sekolah yang banyak yang tersebar di seluruh Indonesia. Masalah tentang sarana dan prasarana PJOK hampir dialami oleh setiap jenjang sekolah baik itu jenjang sekolah SD, SMP maupun SMA, tetapi agar penelitian ini lebih fokus maka Peneliti membatasi subjek penelitian hanya Sekolah Menengah Atas (SMA) yang ada di kecamatan Karangasem. Sekolah Menengah Atas (SMA) baik umum maupun swasta yang ada di kecamatan Karangasem berjumlah 7 sekolah. Lokasi sekolah tersebut sebagian besar berada di kecamatan Karangasem. Dalam penelitian ini ke 7 SMA itu dijadikan sebagai sampel penelitian. Jadi penelitian ini merupakan penelitian populasi.

Hasil pra-observasi yang dilakukan Peneliti di beberapa SMA di kecamatan Karangasem, ditemukan ada beberapa SMA yang sarana dan prasarana pembelajaran PJOK dirasakan masih belum mencukupi dan tidak lengkap. Sekolah-sekolah itu belum memiliki sarana prasarana olahraga seperti alat-alat olahraga atau pun lapangan olahraga yang memadai. Ketiadaan lapangan olahraga di sekolah itu menjadikan kegiatan praktek olahraga harus dilakukan jauh dari lingkungan sekolah, seperti di fasilitas umum Gedung Olah Raga (GOR) atau di lapangan atau taman kota yang kadang harus berbagi lapangan dengan sekolah-sekolah lain, sehingga praktek olahraga menjadi terbatas. Hal inilah yang melatarbelakangi ketertarikan Peneliti untuk mengadakan penelitian berupa survei ketersediaan sarana dan prasarana penunjang pembelajaran PJOK tingkat SMA di Kecamatan Karangasem.

\section{Metode}

Jenis penelitian yang penulis pilih adalah merupakan penelitian deskriptif kuantitatif, dengan menggunakan metode Survei. Menurut (Kanca, 2010) penelitian deskriptif adalah penelitian yang bertujuan untuk mendiskripsikan secara sistematis, faktual dan akurat terhadap suatu populasi, atau daerah tertentu, mengenai sifat dan fakta-fakta tertentu. Dalam penelitian kuantitatif permasalahan yang diteliti sudah jelas, tetap, realitas dianggap tunggal, teramati pola pikir deduktif (Sugiono: 2018). Penelitian ini menggunakan metode survei dimana penulis menanyakan ke beberapa orang (responden) tentang data-data yang ingin penulis ketahui. Dengan menggunakan lembar observasi. Tujuan utama penelitian ini untuk mengetahui ketersediaan sarana dan prasarana penunjang pembelajaran PJOK tingkat SMA di Kecamatan Karangasem.

\section{Hasil dan Pembahasan}

Berdasarkan hasil data penelitian tentang sarana dan prasarana penunjang pembelajaran PJOK di SMA se-Kecamatan Karangasem sudah cukup memadai. Hanya saja belum mendapatkan pengelolaan yang baik, artinya sarana dan prasarana disetiap sekolah tidak diperhatikan baik itu kuantitasnya maupun kualitasnya. Sehingga pada saat pembelajaran yang mengharuskan siswa untuk melakukan praktik terkadang tidak bisa dilakukan secara maksimal karena keterbatasan alat yang akan digunakan. Berikut merupakan tabel hasil penelitian mengenai kondisi sarana dan prasarana olahraga di SMA se-Kecamatan Karangasem beserta status kepemilikan dari sarana dan prasarana tersebut. Sarana yang tersedian di SMA Negeri se-Kecamatan Karangasem adalah 37 jenis, yaitu bola sepak bola, bola voli, bola basket, bola kasti, keset/base, tongkat pemukul, bola softball, tongkat pemukul, keset/base, glove, bola tenis meja, bet, net, shuttle cock, raket, bola tenis lapangan, raket tenis lapangan, peluru, cakram, lembing, tongkat estafet, nomor dada, start block, bendera start, perata pasir atau cangkul, meteran, mistar lompat tinggi, body protector, target bela diri, matras, petiloncat, simpai, tape recorder, papan tolak, kepet renang, 
pelampung, dan papan luncur. Dari 37 jenis sarana dapat diperoleh jumlah total seluruhnya yaitu sebanyak 927 buah yang berkondisi baik yaitu berjumlah 825 atau dengan rata-rata 22,30 dan memiliki persentase $85 \%$. sedangkan yang berkondisi buruk berjumlah 102 dengan rata-rata 2.76 dengan persentase $15 \%$.

Prasarana yang tersedia di SMA Negeri se-Kecamatan Karangasem ini ada 6 jenis yang seluruhnya termasuk kedalam fasilitas. Untuk fasilitas yang tersedia yaitu area bermain dan olahraga, lapangan voli, lapangan basket, lapangan sepak bola, lapangan bulu tangkis dan bak lompat. Dari jumlah total atau kesulurannya yaitu berjumlah 41 dengan rata-rata 6,8 dan persentase $100 \%$ berkondisi baik. Dari segi status kepemilikan prasarana, fasilitas milik sekolah yaitu 8 dengan rata-rata 1,33 dan dengan rata-rata persentase $19 \%$, kemudian untuk fasilitas yang meminjam/menyewa berjumlah 33 dengan rata-rata 5,5 dan dengan rata-rata persentase $81 \%$.

Dari hasil penelitian yang sudah disebutkan diatas tidak semua sekolah memiliki sarana penunjang pembelajaran PJOK yang baik, masih saja ada barang yang rusak dan tidak bisa dipakai. Beberapa sarana yang di miliki oleh sekolah ada yang sudah memenuhi standar untuk jumlahnya ada juga yang belum memenuhi standar, di mana standar tersebut mengacu pada permendiknas No. 24 Tahun 2007 tentang sarana dan prasarana. Oleh karena itu, sarana penunjang pembelajaran PJOK seharusnsya mendapatkan pengelolaan dengan baik dari guru pengampu mata pelajaran tersebut. Pada status kepemilikan sarana penunjang pembelajaran PJOK di SMP seKecamatan Banjar dibedakan menjadi 2 kategori yaitu milik sendiri dan meminjam/menyewa. Dari 605 jumlah keseluruhan atau total sarana yang dimiliki dengan rata-rata 16,35 dan memiliki persentase $100 \%$ milik sendiri. Artinya pada setiap sekolah tidak ada meminjam atau menyewa sarana olahraga di sekolah lain atau di tempat olahraga yang lain.

Berdasarkan keterangan di atas dapat dilihat jika seluruh sekolah memiliki prasarana yang berkondisi baik, namun status kepemilikannya ada yang masih meminjam/menyewa. Di SMP Negeri se-Kecamatan Banjar masih dijumpai kurangnya perawatan terhadap fasilitas yang dimiliki di masing-masing sekolah seperti contohnya lapangan basket yang banyak lubang tidak segera diperbaiki karena jika tidak mendapatkan perhatian lebih lanjut akan berdampak kepada siswa ketika melakasanakan kegiatan pembelajaran. Perawatan fasilitas yang baik juga akan mempengruhi proses pembelajaran siswa karena jika fasilitas tersebut bersih maka bagi yang menggunakan juga akan merasa nyaman.

\section{Simpulan}

Berdasarkan hasil penelitian yang sudah dilakukan maka dapat disimpulkan bahwa sarana dan prasarana penunjang pembelajaran PJOK di SMA Negeri se-Kecamatan Karangasem secara keseluruhan dapat dikatakan sudah cukup baik, namun perlu pengelolaan yang baik. Secara lebih rinci sebagai berikut. 1) Ketersediaan sarana penunjang pembelajaran PJOK di SMA Negeri se- Kecamatan Karangasem jumlah total keseluran dari 7 sekolah tersebut yaitu 927 berkondisi baik 825 dengan rata-rata persentasenya 85\%, yang berkondisi buruk yaitu berjumlah 102 dengan rata-rata persentasenya 15\%. Kemudian dari segi status kepemilikan dari total keseluruhan jumlahnya 927 dengan rata-rata persentase $67 \%$ milik sekolah, 2) Prasarana yang tersedia di SMA Negeri se-Kecamatan Karangasem ini ada 6 jenis yang seluruhnya termasuk kedalam fasilitas. Untuk fasilitas yang tersedia yaitu area bermain dan olahraga, lapangan voli, lapangan basket, lapangan sepak bola, lapangan bulu tangkis dan bak lompat. Dari jumlah total atau kesulurannya yaitu berjumlah 41 dengan rata-rata 6,8 dan persentase $100 \%$ berkondisi baik. Dari segi status kepemilikan prasarana, fasilitas milik sekolah yaitu 8 dengan rata-rata 1,33 dan dengan rata-rata persentase 19\%, kemudian untuk fasilitas yang meminjam/menyewa berjumlah 33 dengan rata-rata 5,5 dan dengan rata-rata persentase $81 \%$. 
Sehubungan dengan hasil penelitian tentang Survei Sarana dan Prasarana Penunjang Pembelajaran PJOK Tingkat SMA se-Kecamatan Karangasem Tahun 2020/2021 sebagian besar dapat dikatakan sudah baik namun, perlu ditingkat lagi dalam segi pengelolaannya agar lebih baik lagi. kepada pihak sekolah SMA Negeri se-Kecamatan Karangasem agar selalu melakukan peningkatan dalam pengelolaan sarana dan prasarana penunjang pembelajaran PJOK dengan sebaik-baiknya, baik itu dalam ketersediannya, kondisinya maupun dari segi status kepemilikinnya agar nantinya semua dapat terkoordinir dengan baik. Disarankan agar peran serta kerjasama antar pemeritnah dengan pihak sekolah dapat berjalan dengan baik, sehingga nantinya tidak ada masalah dalam pengadaan sarana dan prasarana maupun pengelolaannya.

\section{Daftar Pustaka}

Fatmawati, Nur. Andi Mappincara, S. H. (2019). Pemanfaatan dan Pemeliharaan Sarana dan Prasarana Pendidikan. Jurnal Ilmu Pendidikan, Keguruan, Dan Pembelajaran, 3(2), 115-121. https://doi.org/10.26858/pembelajar.v3i2.9799.

Ismaya, B. (2015). Pengelolaan Pendidikan. PT Refika Aditama.

Kanca, I. N. (2010). Metode Penelitian Pengajaran Pendidikan Jasmani dan Olahraga. Universitas Pendidikan Ganesha.

Megasari, R. (2014). Peningkatan Pengelolaan Sarana dan Prasarana Pendidikan untuk Meningkatan Kualitas Pembelajaran di SMPN 5 Bukittinggi. Jurnal Administrasi Pendidikan, Bahana Manajemen Pendidikan, 2(1), 636-831. http://ejournal.unp.ac.id/index.php/bahana/article/viewFile/3808/3041

Natal, Y. R., \& Bate, N. (2020). MANAJEMEN PENGELOLAAN SARANA DAN PRASARANA PJOK. 9(2), 70-82. https://ejournal.unsri.ac.id/index.php/altius/index

Nursalam, 2016, metode penelitian. (2013). Peranan Sarana Dan Prasarana Terhadap Motivasi Belajar Pada Pembelajaran Pendidikan Jasmani Olahraga Dan Kesehatan Di Sma Negeri 3 Banda Aceh. Journal of Chemical Information and Modeling, 53(9), 1689-1699.

Purnama, S., \& Siliwangi, U. (2017). Pengaruh Manajemen Fasilitas Olahraga Dan Layanan Guruterhadap Efektivitas Pendidikan Jasmani Olahraga Dankesehatan (Studi Pada Sekolah Menengah Atas Negeri di Kota Tasikmalaya). Jurnal Sport Area, 105-114.

Suryobroto, A. S. (2004). Diktat Mata Kuliah Sarana dan Prasarana Pendidikan Jasmani. Universitas Negeri Yogyakarta. 